\title{
Assessing the Decadal Impact of China's Sloping Land Conversion Program on Household Income under Enrollment and Earning Differentiation
}

\author{
Hua $\mathrm{Li}^{1}$, Shunbo Yao ${ }^{1}$, Runsheng Yin ${ }^{2,3, *}$, and Guangquan $\mathrm{Liu}^{4}$ \\ ${ }^{1}$ College of Economics and Management, Northwest A\&F University, Yangling712100, China \\ ${ }^{2}$ College of Economics and Management, Wuhan Polytechnic University, Wuhan 430023, China \\ ${ }^{3}$ Department of Forestry, Michigan State University, East Lansing, MI 48824, USA \\ ${ }^{4}$ International Center for Erosion and Sedimentation Research and Training, Chinese Academy \\ of Water Resources, Beijing \\ * Author to whom correspondence should be addressed; Tel: (517) 432-3352; E-mail: \\ yinr@msu.edu
}

Abstract: This study hypothesizes that the income levels of households are affected by their different areas enrolled in the Sloping Land Conversion Program, the local economic condition, and the statuses of their previous earnings. We test these relationships by running quantile regressions with data collected from 182 households in the Loess Plateau region covering the period of 1998-2011. We find that the more cropland was retired, the more subsidy was received, and the more labor was set free from farming, which, in turn, led to a larger decrease in farming income but a much larger gain in off-farm income. Further, the area enrolled had a more positive effect during 1998-2004 than that during 2006-2011 on all households; and the positive effect was significant only on those households of the $0.25^{\text {th }}$ and $0.50^{\text {th }}$ income quantiles later. Also, the proportion of off-farm labor to total labor, the off-farm work time, and the local GDP per capita had a larger income effect in the later sub-period, especially for households in the $0.75^{\text {th }}$ and $0.90^{\text {th }}$ income quantiles. These results carry major implications in terms of how to reduce poverty and increase income in ecologically fragile regions in and outside of China and how to assess the effect and effectiveness of any ecological conservation program.

Keywords: Ecological restoration, payments for ecosystem services, labor transfer, household income change, poverty alleviation, quantile regression 


\section{Introduction}

In 1999, China launched the Sloping Land Conversion Program (SLCP) — the largest ecological restoration, or payments for ecosystem services (PES), initiative in the developing world (Liu et al. 2008, Bennett 2008). The SLCP aims to reverse the country's environmental deterioration by retiring and converting degraded cropland while improving farmers' livelihoods, especially those of the rural poor (State Forestry Administration, or SFA, 2003). The program provides financial incentives to farmers who establish forest or grass cover on retired cropland in order to "supply" ecosystem services, such as reduction of water runoff and soil erosion, and prevention of flooding (Yin 2009).

Given the substantial funding of over 300 billion yuan thus far (SFA 2013) ${ }^{1}$ and the broad attention that the PES program has garnered, there have been extensive assessments of the extent to which it has met its objectives (e.g., Liu et al. 2008, Yin 2009, Li et al. 2011). While studies generally agree that the income impacts of the program vary in terms of the levels of cropland enrollment and the statuses of family earnings (e.g., Liu and Zhang 2006, Yao et al. 2010, Groom and Palmer 2012), it remains rare to look explicitly into the income impacts in light of these differences. In particular, it is still unclear whether or not the poor farmers have benefitted more than proportionately from participating in the program. The goal of this paper is to address these issues by evaluating the income effects of the SLCP in a more disaggregate and nuanced manner.

Among the program practitioners and analysts, a consensus is that household income growth is an important indicator of the impact and sustainability of the SLCP (Liu et al. 2008, Uchida et al. 2007). Implementing the SLCP has both direct and indirect impacts on household income (Yin et al. 2014, Lin and Yao 2014, Liu et al. 2010). The direct effect is reflected mainly in the government subsidies relative to the lost income from grain and livestock production. The

${ }^{1} \$ 1=6.15$ yuan in March 2014. 
initial duration of the subsidy was set at eight years for the period of 2001-2008, with a grain compensation of 2,250 kg/ha in the Yangtze River Basin and 1,500 kg/ha in the Yellow River Basin (Xu et al. 2004). In addition, an annual cash outlay of 300 yuan/ha was universally adopted for tending and protecting the planted trees and other established vegetation covers. Due to the dwindling public grain stocks, however, since 2004 the grain compensation has been replaced with a cash payment at a constant rate of 1.4 yuan $/ \mathrm{kg}$ (Xu et al. 2004). To continue the ecosystem recovery and to improve the program's cost effectiveness, in 2007 the central government decided to extend the subsidy for another eight years but to reduce the cash compensation for lost grain yields to half of the previous levels (Yin and Yin 2010).

The SLCP's indirect impact on household income is captured mostly in the earnings from adjusting the production and employment structures induced by the SLCP (Lin and Yao 2014, Yin 2009). Indeed, households participating in the SLCP have experienced substantial transformations in these respects. While cropland area has decreased sharply, farming on remaining cropland has become more intensive and animal husbandry switched from open grazing to pen-raising (Yao et al. 2010, Liu et al. 2013). At the same time, the SLCP has enabled the rural labor force freed from farming to seek and obtain off-farm jobs in and outside of their locales and the non-farming income generated has become a very large component of the household total income (Yin et al. 2014, Lin and Yao 2014, Xu et al. 2006).

One question of common interest is to what extent the substantial household income gain has been driven by implementing the SLCP and whether this effect has to do with the heterogeneity of cropland retirement intensity and the status of household earnings (Zhao et al. 2015). In fact, a large body of literature has focused on answering this question. For example, Uchida et al. (2005) find that the average household net income increased considerably for the 
SLCP participants in Ningxia and Guizhou. Similarly, Liu and Zhang (2006) detect a positive impact of converting farmland to forests on household income in the proximity of Beijing and Tianjin. The evidence generated by Xie et al. (2005), Yao et al. (2010), and Li et al. (2011) also confirms a positive income effect, a larger part of which has indeed come indirectly from the structural adjustment and labor transfer into off-farm sectors.

More notably, Groom and Palmer (2012), using quantile regressions and pooled data from Ningxia and Guizhou, report that the SLCP's impact on household income was significantly positive at the lower quantiles of the income distribution, compared to their nonparticipating counterparts. The use of quantile regressions to assess the potentially differentiated income impacts is a novel step, but the data these authors used cover a short period of time (only 1998 and 2004). So, their study was unable to examine the more recent situation, particularly after 2008 when the subsidy was cut back substantially. Moreover, they did not consider the possible effects of such factors as on- and off-farm work times, on household income.

In contrast, $\mathrm{Xu}$ et al. (2004) show that the growth rates in average income varied across regions over the period of 1999-2003, but the overall impact of the SLCP on participants' income was insignificant. Uchida et al. (2007) identify only a moderate success of the SLCP in achieving poverty alleviation; further, they fail to obtain evidence to support the claim that participating households have shifted more of their work time into off-farm wage-earning or selfemploying activities. Wang and Maclaren (2012) even go so far as to assert that $58 \%$ of the families participating in the program considered themselves worse off after getting enrolled; also, farmers in the Wolong Nature Reserve intended to reconvert $22.6 \%$ of the land enrolled in the SLCP to farming after the end of the subsidies, and the land to be reconverted in northern Shaanxi could amount to $37.2 \%$ of the enrolled total. 
Different, and often contradictory, conclusions have been drawn on household poverty reduction and income growth in previous studies. Why is this? First, most of the studies have focused on the income impact of the entire sample, without looking into the potentially differentiated impacts corresponding to the variable levels of SLCP enrollment (Zhao et al. 2015). Second, the datasets used in many studies have short-time coverages, either before 2006 (Xu et al. 2004, Uchida et al. 2005, Groom and Palmer 2012, Liu and Zhang 2006), or only after 2006 (Yao et al. 2010, Wang and Maclaren 2012), which may be inadequate to capture changes in the SLCP's income effects over time. Moreover, the program's effect and effectiveness are ultimately predicated on the internal and external local conditions under which it has been executed (Yin et al. 2010). Therefore, it is crucial to identify these conditions and incorporate them into an impact assessment.

In this article, we attempt to overcome the limitations of the previous studies of the SLCP's impact on poverty alleviation and income growth. We will do so, first, by using household survey data that cover a long period (1998-2011) and at the same time adopting alternative estimation strategies to reflect the subsidy regime shift. Second, we will classify the sample households into multiple groups according to their land areas enrolled and earnings to capture the potentially differentiated income effects of participating in the program, with particular attention given to those poor families. It is expected that based on appropriate quantile regressions (Meyer and Sullivan 2013, Zhang et al. 2005), these steps will generate a rich set of empirical results and thus make a timely contribution to better understanding of the program's effect and effectiveness. Further, we hope that our work will shed light on how to properly assess similar ecological restoration efforts in other parts of the world.

The remainder of this paper is organized as follows: the next two sections describe the 
study site and survey data, following which the empirical model and estimated results are then presented, and closing remarks are made in the final section.

\section{Study site}

Our data for evaluating the income change induced by implementing the SLCP came from multiple rounds of household surveys conducted in the county of Wuqi in northern Shaanxi province (Figure 1). Before discussing our surveys and presenting our data, it is worthwhile to provide a brief description of the county and the structural change of farmer's income there since the end of last century.

\section{$<$ Insert Figure 1 here $>$}

Situated in the northwest of Yan'an municipality, Wuqi had a total population of 127,369 in 2011. While the official demographic statistics show that the county's rural residents remained close to 110,000 , more than a half of the rural labor had been involved in off-farm and/or offvillage employment and business activities (Wuqi Statistics Bureau 2012). Before 1998, Wuqi had a cultivated land base of 123,700 ha, and a majority of the rural households also raised goats, whose population peaked to 280,000 in the late 1990 s. As a consequence of extensive farming and open grazing, the county's land and vegetation were heavily degraded, making the problems of water runoff, soil erosion, and flash flooding extremely severe.

In response, the county began retiring croplands on steep slopes and converting them to forest and/or grass covers in 1998. Taking advantage of the national initiative, the county's setaside of marginal cropland expanded tremendously in 1999-two years ahead of most other places across the country. Quickly, cropland was cut back to only 10,730 ha, and open grazing was completely banned (Wuqi SLCP Office 2012). To facilitate the ecological and economic 
transformation, the county government has invested heavily in such activities as improving the quality of the remaining farmland, introducing new breeds of crops and animals, and promoting best land-use practices, complementing the national ecological restoration initiative. As such, Wuqi was later selected by the provincial and central governments as a model county in pioneering cropland retirement and restoration (Yao et al. 2010). It was based on these developments that our research team decided to monitor the program implementation and its impacts there since 2005 .

Table 1 summarizes farmer's per-capita incomes from different sources from 1998 to 2011. ${ }^{2}$ It can be seen that total income witnessed a remarkable increase over the period-from 1432 yuan in 1998 to 1968 yuan in 2004 and 3794 yuan in 2011. Farming income decreased from 947 yuan in 1998 to 482 yuan in 2006 and then rebounded to 695 yuan in 2011. Similarly, animal husbandry income decreased from 396 yuan in 1998 to 110 yuan in 2004 and slightly recovered to 180 yuan in 2011. Starting at 481yuan in 1999, income from the SLCP subsidies rose to 883 yuan in 2004 and declined to 643 yuan on average in 2011. Meanwhile, the government began to subsidize farming in 2004 as well (at a level of only 16 yuan per capita), which rose to 213 yuan in 2011. In comparison, off-farm income rose from merely 89 yuan in 1998 to 428 yuan in 2004 and then to 1783 yuan by 2011.

\section{<Insert Table 1 here $>$}

In sum, farming was the dominant source of income to all of the households in 1998 before they joined the SLCP, which, along with the strong economic growth, triggered the transformation of agriculture, the adjustment of local economy, and the transfer of labor into offfarm sectors. As a result, off-farm work has become the major source of family revenues. Despite the sharp reduction of income from crop and livestock production, the gains in off-farming

\footnotetext{
${ }^{2}$ The use of per-capita based figures helps avoid the cofounding effect of household size variation over time.
} 
income and program subsidies have much more than offset the income losses from crop and livestock production.

\section{Household data}

Our research team carried out repetitive surveys of 200 randomly chosen households in Wuqi in 2005, 2007, and 2012. In our first survey in 2005, we asked the sample households to provide the relevant information for 2004 and 1998, based on a detailed questionnaire that we had designed following focus group interviews and pre-tests. Because of the late initiation of our survey, however, we were concerned that recalling what had happened in 1998, which was several years earlier, might not give rise to information as accurate and reliable as that for the immediately past year (2004). But later we discovered that family incomes were generally low and did not vary much before the SLCP was initiated. ${ }^{3}$ Subsequent visits to the selected households in 2007 and 2012 generated data for 2006 and 2011, respectively. Notably, 1998 is the last year before the SLCP was formally launched in Wuqi; 2004 is the year when the program enrollments almost peaked and thus did not gain much thereafter; 2006 is the year when the original eight-year program duration expired there and the government decided to continue subsidizing farmers for another eight years, but at reduced levels; and 2011 is the year of our last survey.

Because some of the sample households migrated to other places after 2005 or failed to provide certain family information in the subsequent surveys upon close cross-checks, we derived an effective sample of 182 households throughout the period of 1998-2011. In addition to cropland retirement and demographic features, our questionnaire included production activities (farming, forestry, and other) and the corresponding labor times, the distance to the nearest town, and the destinations of off-farm work-outside of the province, outside of the

\footnotetext{
${ }^{3}$ See Table 1 and our survey data summary below for more detail.
} 
county but inside the province, and inside the county. In addition, we gathered essential statistics of local economic conditions to supplement our analysis. All the nominal monetary indicators were deflated with the county's Producer Price Index or Consumer Price Index, respectively, with 1998 as the base year. To our knowledge, this is one of the few comprehensive and up-todate survey-based panel datasets regarding the SLCP implementation and economic impact, in spite of its limited spatial scope.

The basic production and employment dynamics and demographic features of the surveyed households are listed in Table 2. It can be seen that they had virtually completed their cropland enrollment into the SLCP by 2004 - with an average amount of 2.57 ha per household, which later stabilized at 2.74 ha. However, the areas of individual enrollments varied a great deal - the lowest being 0.66 ha and the highest being 12 ha per household. Meanwhile, the average amount of cultivated land decreased from 3.39 ha per household in 1998 to 0.81 ha in 2004, and it later expanded slightly due to terracing and/or leveling efforts. Accordingly, farming became more intensive. The expenditure on commercial inputs (such as fertilizers, improved seeds, and crop cover sheets) increased from 560.6 yuan per ha in 1998 to 1428.2 yuan in 2004; the average farming time increased from 143.4 days per ha in 1998 to 236.3 days in 2004. After 2004, however, the per ha cash expenses and labor time in farming declined a bit because of an increasing amount of labor having already moved into off-farm sectors and relatively low returns to farming activities (Yin et al. (2014). In the meantime, off-farm work time increased from 10.5 days per family in 1998 to 231.8 days in 2011 .

\section{$<$ Insert Table 2 here $>$}

Table 3 further reveals the potential linkages between varied areas enrolled in the SLCP (in 2006) and per-capita subsidy/income by dividing the whole sample into three groups 
according to the extent of per-household enrollment - those having less than 1.3 ha enrolled (29.6\%), those having an enrollment of $1.3-2.0$ ha $(26.4 \%)$, and those having more than 2.0 haenrolled $(44.0 \%)$. For the group with an enrolled area below 1.3 ha, the SLCP subsidy accounted for $36.3 \%$ of the per capita income in 2004 , which declined to $25.5 \%$ in 2006 and $10.9 \%$ in 2011 . For the group with an enrollment of $1.3-2.0$ ha the proportion of the program subsidy in total income was $49.9 \%$ in 2004 and dropped to $35.4 \%$ in 2006 and $15.9 \%$ in 2011. For the group with an enrollment of above 2.0 ha, the program subsidy amounted for $61.8 \%$ of total income in 2004, 46.4\% in 2006, and $27.2 \%$ in 2011.

\section{<Insert Table 3 here $>$}

Similarly, for the group with an enrolled area less than 1.3 ha, farming income declined from 781.5 yuan per capita in 1998 to 451.5 yuan in 2004, and rebounded to 1186.8 yuan in 2011. In other words, the proportion of farming income (including subsidies since 2006) in total income was $72.2 \%$ in 1998 but dropped to only $29.1 \%$ in 2004 and then increased to $45.3 \%$ in 2011. For the group of enrolled land in the range of 1.3-2.0 ha, farming income decreased from 965.7 yuan per capita in 1998 to 389.9 yuan in 2004 , and finally rose to 932.9 yuan in 2011 . Put differently, the proportion of farming income to total income was $62.4 \%$ in 1998 , but declined to $23.4 \%$ in 2004 and then rose to $29.4 \%$ in 2011 . For the group with an enrolled area above 2.0 ha, farming income decreased from 1332.2 yuan per capita in 1998 to 536.1 yuan in 2011 and, accordingly, the proportion of farming income to total income declined from $73.2 \%$ in 1998 to $12.6 \%$ in 2011 .

In contrast, for the group with an enrolled area below 1.3 ha, off-farm income increased from 82.0 yuan per capita in 1998 to 1352.0 yuan in 2011 , leading the proportion of off-farming income to total income to increase from $6.6 \%$ in 1998 to $46.2 \%$ in 2011 . Likewise, for the group 
with an enrolled area in the range of 1.3-2.0 ha, off-farm income increased from 84.2 yuan per capita in 1998 to 1663.5 yuan in 2011 (namely, from 6.1\% to 51.5\%). For the group with an enrolled area above 2.0 ha, off-farm income rose from 94.0 yuan per capita in 1998 to 2676.1 yuan in 2011 (or from $5.4 \%$ to $56.8 \%$ ).

In short, we have observed that the more cropland was retired, the greater amount of subsidy was received and the more rural labor was set free from farming; and as a result of these changes, large reduction in farming income and even larger gain in off-farm income occurred. However, these effects are mediated by the statuses of household earnings and external factors including the local economic conditions. Meanwhile, the household income gap enlarged. For instance, family income for the group with the largest enrollment ( $>2$ ha) was $38.1 \%$ higher than that of the group with the smallest enrollment $(<1.3 \mathrm{ha})$ in 1998, but that gap swelled to $61.1 \%$ in 2011. Figure 2 presents the distribution of per capital income and its shift over time.

\section{$<$ Insert Figure 2 here $>$}

Therefore, it is essential to divide the whole sample into separate income quantiles in identifying the differentiated effects of the major determinants. Of course, this is more appropriate analytically; but more importantly, it will enable us to clearly identify the program's effect on poverty alleviation and livelihood improvement (Groom and Palmer 2012).

\section{Empirical model}

Unlike other studies, though, all of our sample households have participated in the SLCP, albeit with different levels of enrollment. The universal participation means that no control group is available for identifying the impact of program participation using a conventional treatment effect model, such as the difference in differences one (Uchida et al. 2007, Yao et al. 2010). 
Nonetheless, we argue that it is still possible to conduct a meaningful analysis of the impact if our data contain sufficient variation in terms of the extent of participation and income distribution (Furno 2013), as we have shown. In other words, what we intend to pursue is to assess the differentiated income effects induced by the varied levels of program participation and the change subsidies.

Here, we follow the strategy adopted by Finkelstein (2007) in measuring the effect of health insurance. Because the introduction of Medicare in the U.S. affected the whole nation, empirical researchers have found it difficult to construct a counterfactual that can be used to understand how the presence of Medicare has affected the healthcare marketplace. The author devised an insightful strategy to circumvent this difficulty by comparing the effect of the introduction of Medicare on hospital expenditures by elderly households in different regions of the country (Finkelstein, 2007). Her rationale is that prior to introducing Medicare, the incidence of hospitalization insurance policies varied widely across regions, so the fraction of elderly households who experienced changes in their ability to pay for hospital-based care when Medicare was introduced also varied across regions. That is, even though the policy change was national, the effect of that policy relative to the prior situation varied substantially across regions.

As far as our case is concerned, we have already shown that the income statuses and the extents of program enrollment varied across households. Our earlier description has also made it clear that the more cultivated land is enrolled into the SLCP, the greater is the amount of time that household members spent in off-farm jobs, which in turn enhances family income in a major way. Moreover, these effects also vary across different levels of household earnings. Therefore, it appears that this is a case well suited for quantile regression (QR) (Furno 2013), which allows us to analyze not only the median but also the lower and the upper quantiles (Koenker and Bassett 
1978).

Consistent with previous studies (Uchida et al. 2007, Liu et al. 2010, Groom and Palmer 2012) and our discussion above, we posit that the income of a household is a function of its participation in the SLCP as well as a set of well-identified covariates, including inputs used in farming and non-farming activities, total availability of family workforce, and local economic condition, among other factors. More specifically, our basic linear conditional quantile function is defined as:

$$
Y(\tau \mid x)=\alpha+\beta_{i} X_{i}+\gamma_{j} T_{j}+\delta_{j} X_{1} T_{j}+\mu \text { for } i=1,2,3 \ldots, 12 ; j=1,2,3
$$

where $Y$ is the natural logarithm of household income; $X_{1}-X_{5}$ (all in natural logarithm) are, respectively, household's land enrolled in the SLCP, cultivated land area, farming expenditure, farming time, and off-farm work time; $X_{6}-X_{10}$ are the ratio of off-farm to total labor time, the destination dummy of off-farm work ( 1 if inside the county, 2 if outside of the county but inside the province, and 3 if outside of the province), the number of family laborers, township-level per capita GDP (in natural logarithm), and the ratio of retired cropland to total cropland area in 1998 for each township; $X_{11}$ is the ratio of farming subsidies to total income; $X_{12}$ is the product of the ratio of off-farm to total labor time $\left(X_{6}\right)$ and the ratio of retired cropland to total cropland area in $1998\left(X_{10}\right) ; T$ is a set of time dummy variables $\left(T_{1}=1\right.$ for 2004,0 otherwise; $T_{2}=1$ for 2006,0 otherwise; $T_{3}=1$ for 2011,0 otherwise); $\alpha, \beta_{i}, \gamma_{j}$, and $\delta_{j}$ are the parameters to be estimated; and $u$ is the error term.

We argue that using the actual amount of cropland enrolled in the SLCP $\left(X_{1}\right)$ is more appropriate for capturing the effect of its contribution to household income. Likewise, we include township-level per capita GDP $\left(X_{9}\right)$ to reflect the potential effect of the local economic condition on a household's income to avoid overestimating the program impact, the ratio of retired 
cropland to total cropland area in 1998 for each township $\left(X_{10}\right)$ to capture the variability of each township's cropland available for participating in the program, the ratio of farming subsidies to total income $\left(X_{11}\right)$ as another contributor to income growth, and the product $\left(X_{12}\right)$ of the ratio of off-farm to total labor $\left(X_{6}\right)$ and the ratio of retired cropland to total cropland area in $1998\left(X_{10}\right)$ to capture their possible interactive effect on family income. The aim of incorporating dummy variables $T_{1}, T_{2}$, and $T_{3}$ is to capture the trend effect, if any, associated with external changes of the economic condition over time (Wooldridge 2002, Yin 2009). We also include the interactive terms $\left(X_{1} T_{t}\right)$ of a household's subsidy from participating in the SLCP $\left(X_{1}\right)$ and the time dummy variables $T_{j}$ to detect whether changed subsidy regime has actually caused a different effect of the program subsidy on household income over time. For our analytic purpose, the four chosen quantiles are $\tau \in\{0.25,0.5,0.75,0.90\}$.

The above model will be estimated with data for the whole period of 1998-2011 under the four quantiles as well as the lumped-up case for comparison. Alternatively, to explicitly determine the impact of the subsidy regime shift after 2007 on household income as well as to reflect the further improved economic conditions, we will also explore a different strategy of estimation by running separate regressions for the two sub-periods-1998-2004 and 2006-2011. Further, given the nature of our sample data — repetitive surveys over a long period, we maintain that fixed-effects estimation would be more appropriate, compared to the random-effects counterpart that assumes either little variation or similar change in the control variables over time.

Lastly, it is necessary to assume no selection bias in household's participation to obtain consistent estimates (Xu et al. 2004, Yin et al. 2010). Because the SLCP is a governmentsponsored program, a household's participation was, by and large, not based on its own selection. 
Indeed, our interviews indicated that households had little choice regarding the specific tracts or sizes of farmland to be converted or the trees to be planted. Thus, we will take the argument made by Xu et al. (2004) and Uchida et al. (2005), who claimed that farmers' self-selection in SLCP participation could be ignored. In fact, this argument has been recently validated by Yin et al. (2014), whose statistical testing rejected the hypothesis that there exists farmers' selfselection in SLCP participation.

\section{Estimated results}

In general, the goodness of fit of the different versions of our empirical model is quite reasonable, while regressions for the whole period feature slightly higher $R^{2}$ values. Further, the outcome of the fixed-effects estimation indeed outperforms that of the random-effects counterpart in terms of the goodness of fit and the significance of coefficients. Our results unequivocally demonstrate the relevance and power of quantile-based regressions, instead of those using lumped-up data. Table 4 shows that during the whole period, the amount of cropland enrolled in the SLCP has had a positive income impact of $14 \%$, which is modestly significant, if the data are lumped up in a single regression. In contrast, based on separate regressions, the amount of cropland enrolled in the SLCP has made a much larger contribution to the income of those households in the lower quantiles at greater significance level $-29 \%$ for the $0.25^{\text {th }}$ quantile and $21 \%$ for the $0.50^{\text {th }}$ quantile. But the same effect becomes no longer significant for households in the other two upper income quantiles.

\section{$<$ Insert Table 4 here $>$}

Differences are also revealed in the coefficients of many other variables and the levels of their significance in the QRs. Thus, we will no longer relate them to those of the regressions 
based on lumped data heretofore in reporting our findings. It can be seen that farming expenditure, off-farm work time, the ratio of off-farm labor to total labor, the destination of offfarm work, local per-capita GDP, and the ratio of retired to total cropland area in 1998 are all positive at certain levels of significance. On the other hand, area of cultivated land has a tiny positive income effect only on families in the $0.25^{\text {th }}$ income quantile at the $95 \%$ significance level. Similarly, the coefficients of farming time and subsidy are somewhat significant for households in the $0.25^{\text {th }}$ and $0.50^{\text {th }}$ income quantiles, but it is insignificant for households in the $0.75^{\text {th }}$ and $0.90^{\text {th }}$ income quantiles. The small, positive coefficient of the number of family laborers is only significant in the two upper quantiles. The coefficient of the interactive term between the ratio of off-farm labor to total labor and the ratio of retired cropland in a given year to total cropland prior to the program is significantly positive, and its magnitude is larger for households in the higher quantiles.

Moreover, the coefficients of the three time dummy variables are positive at various levels of significance, suggesting a persistent trend effect. Again, the higher the income quantile, the stronger the effect is. The coefficients of the interactive terms of a household's subsidy from participating in the SLCP and the time dummies further indicate that for a given quantile, the effect of program subsidy peaked in 2006 and the reduced subsidy thereafter had a diminished effect on household income. Prior to the subsidy regime shift, though, the higher the quantile, the more pronounced the interactive effect was.

Tables 5 and 6 list the estimated results for the two sub-periods-1998-2004 and 20062011. Notably, the estimated income impacts of the SLCP, as well as several other variables, are quite different from those derived from the QRs based on data for the whole period. First, the SLCP subsidy policy in the earlier period has a much greater effect on income of all households 
than that in the later period. Second, the coefficient is significant in all quantiles in the earlier period, while it remains so only in the $0.25^{\text {th }}$ and $0.50^{\text {th }}$ income quantiles later. Additionally, the area of cultivated land has a significantly positive effect on the income of households in the $0.25^{\text {th }}$ and $0.50^{\text {th }}$ quantiles in the earlier period, but it is no longer significant at all in the later period. Farming expenditure has a positive effect on the income of all households in the two subperiods; and, again, its effect is diminished during the later sub-period. Also, the lower the quantile, the larger the magnitude of the coefficient is. Farming time has a positive, albeit small, income effect on households in the $0.25^{\text {th }}$ and $0.50^{\text {th }}$ quantiles at the $95 \%$ significance level during 1998-2004; later, it maintains a tiny positive effect only on the lowest quantile. For households in the two upper quantiles $\left(0.75^{\text {th }}\right.$ and $\left.0.90^{\text {th }}\right)$, that variable has an insignificant effect during both sub-periods. The coefficient of farming subsidies is significant only to households in the lowest quantile in the first sub-period, but it is so to households in the two lower quantiles in the second sub-period with enhanced magnitudes.

\section{$<$ Insert Tables 5 and 6 here $>$}

Off-farm work time has a significant positive effect on the income of all households in the two sub-periods, and that effect is generally larger in the second sub-period than in the first. The coefficient is significant at the $99 \%$ level for the $0.75^{\text {th }}$ and $0.90^{\text {th }}$ quantiles and at lower significance levels for the $0.25^{\text {th }}$ and $0.50^{\text {th }}$ quantiles. Likewise, the proportion of off-farm labor in total labor has a significantly positive effect on household income in all quantiles in the two sub-periods; the effect is generally larger in the second sub-period than in the first, and the higher the income quantile the larger the effect. The off-farm destination dummy has a small, positive effect on households in all but the lowest income quantiles during the two sub-periods. The number of family laborers has a significantly positive effect across the quantiles during 1998- 
2004, while its effect is somehow significant only on households in the two upper quantiles later.

The per-capita GDP and the ratio of retired cropland to total cropland area in 1998 in each township have a strong, positive effect on household income in all quantiles in the two subperiods. Furthermore, the effects of these two variables become even larger in the second subperiod than in the first, and they are generally larger for households in the higher quantiles. Similarly, the interaction between the ratio of off-farm to total labor and the ratio of retired cropland to total cropland area in 1998 is significant in all cases, but its effect tends to be more pronounced in the upper quantiles and during the later sub-period. The trend effect is positive at various levels of significance, and the coefficients of the upper quantiles are much larger. The coefficient of the interactive term between the program subsidy and the time dummy, again, shows that the reduced subsidy diminished its effect on household income; prior to the subsidy regime shift, however, the interactive effect was more prominent in the higher the quantiles.

\section{Discussion and conclusions}

We set out to test the hypothesis that household income in places where the SLCP is implemented is determined by different areas enrolled in the program, local natural and economic conditions, and household standings in different income quantiles, among other factors. As a key part of this endeavor, we decided to address the question of whether or not the rural poor have benefitted more than proportionately from their participation in the program. To that end, we have estimated an empirical model with alternative strategies and data collected from 182 households in Wuqi of the Loess Plateau region, covering the period of 1998-2011.

Our results have confirmed the logic of our conceptual reasoning for running QRs, the plausibility of our model identification, and the appropriateness of our estimation strategies. 
Because the dependent variable and many of the independent variables of our model are transformed logarithmically, the corresponding coefficients can be interpreted as elasticities. Due to space limit, however, we will leave this task to interested readers.

First, we have demonstrated that farming income was the dominant source of income common to all of the households in 1998; thereafter, implementing the SLCP, coupled with rapid economic growth, triggered the transformation of agricultural production and the transfer of rural labor into off-farm sectors. Overall, the SLCP subsidy accounted for over $30 \%$ of per-capita total income in 2004 and at least $11 \%$ more recently. Given this variation as well as that across income quantiles, we argued that it is more sensible to run QRs separately for the two subperiods (1998-2004 and 2006-2011). Our results show that the subsidy policy in the earlier period has a greater effect on income of all households than that in the later period, and the estimated coefficient of participating in the SLCP is significantly positive in all quantiles earlier but only so in the two lower income quantiles $\left(0.25^{\text {th }}\right.$ and $\left.0.50^{\text {th }}\right)$ later. Consistent with what was reported by Groom and Palmer (2012) and Wang et al. (2012), this suggests that the income impact of the SLCP on households in the higher-income quantiles lasted for a shorter duration, implying that the program has been largely successful in achieving its objectives of environmental restoration and poverty reduction.

In contrast, if we run the QRs based on data for the whole period (1998-2011), the estimated coefficient of SLCP enrollment is never significant to households in the two upper income quantiles, which seems less reasonable and convincing. Meanwhile, the coefficients of the interactive terms between program subsidy and time dummy variables indicate a large drop of the subsidy effect in 2011 following a peak in 2006. The finding that a larger area of cropland enrolled in the SLCP resulted in a greater direct impact of the SLCP on household income, 
especially during earlier sub-period (1998-2004), confirms what was previously reported by Liu et al. (2006) and Uchida et al. (2005). But this result differs from the conclusion drawn by Zhang et al. (2005) that the SLCP had a significantly positive income impact only on the poor farmers.

Also, our analysis has revealed that off-farm work time has a significantly positive effect on the income of all households in the two sub-periods, and the effect becomes even larger in the second sub-period. Likewise, the proportion of off-farm labor in total labor time has a significantly positive effect on household income in all quantiles in the two sub-periods, and the effect is larger in the second sub-period as well. In addition, the destination of off-farm work has a positive, albeit small, effect on households in all but the lowest income quantiles during the two sub-periods. Taken together, these results suggest that off-farm job and earning opportunities were more important to households in the higher income quantiles than to those in the lower ones; and their importance was strengthened during the later years of our sample coverage. Put differently, implementing the SLCP was aided tremendously by the plentiful job opportunities in the township and urban areas, allowing rural labor to find jobs and generate significant amount of off-farm income. Should this condition have not existed, the program would not have been so successful in transferring the large amount of displaced labor into non-farming sectors of the economy, resulting a lot of idled rural labor. Policymakers in other parts of the world should be cognizant of this situation if and when they are conceiving similar programs.

Our analysis has further found that the area of cultivated land has a positive effect on the income of all but households in the $0.75^{\text {th }}$ and $0.90^{\text {th }}$ quantiles during 1998-2004, whereas its coefficient becomes insignificant for households of all quantiles thereafter. This outcome is unsurprising, however, given the large reduction of cultivated land by 2004 and limited profitability of farming (Yin et al. 2013). Farming expenditure has a more positive income effect 
on all households during 1998-2004 than during later years. The effect of labor time spent on farming is significant for households early on in the $0.25^{\text {th }}$ and $0.50^{\text {th }}$ quantiles but only barely significant to households in the lowest quantile later. In combination, these results indicate that farming was more important to households in the lower quantiles than to those in the higher quantiles in the early sub-period; but the importance of farming faded away later, along with the economic transformation (Yin and Zhao 2012).

The local township-level per capita GDP and ratio of retired cropland to total cropland area in 1998 have significant positive effects on household income in all quantiles in the two sub-periods. Also, the effects of these two variables even become larger in the second sub-period than in the first. Additionally, the interaction between the ratio of off-farm to total labor and the ratio of retired cropland to total cropland area in 1998 is significant in all cases, but the income effect tends to be more prominent in the upper quantiles and during the later sub-period. These findings illustrate that a better-developed local economy and a greater extent of program participation are more beneficial to households, especially to those in higher income brackets (Yin et al. 2013).

Moreover, our analysis indicates that the local towns and county seat used to be the primary destinations of off-farm work. With the leveling off of local energy production in recent years, off-farm opportunities in Wuqi county have become more limited in absorbing the surplus labor from low-income households and continuing the transformation of the local economy (Yi et al. 2006, Liu et al. 2006, Wang et al. 2012). Fortunately, government and business entities have made progress in exploring alternative employment options, such as expanding vegetable and fruit production and creating new and high-yield cropland by means of terracing and leveling, among other things (Yao et al. 2010). 
Going forward, it is thus necessary for the government to target the subsidy toward lowincome households, particularly those with larger amounts of cropland enrolled in the SLCP and/or less off-farm labor market participation to avoid any potential reconversion (Yin et al. 2014). Likewise, the local agencies should continue promoting economic development and exploring means, such as information service, credit provision, and technical training, to provide a better and more supportive external economic setting to sustain the restored ecosystems and income growth. At the same time, it is necessary for communities to intensify crop production on reduced cropland to absorb more surplus labor and further increase food productivity (Yao et al. 2010). In this regard, it's an important step to provide essential farming subsidies; however, they have so far been effective only to those households in the two lower income quantiles.

Finally, it is worth noting that because the data used in this study cover only one county, in which all of the households have participated in the SLCP, our findings of the income effects of program participation as well as other factors may not apply to other places, especially those with local situations different from that of Wuqi. To reach a broader conclusion, more data reflecting the local social-ecological conditions should thus be collected and a clear baseline established in the future. Of course, follow-up work ought to be pursued to examine what happens to the sample site of this study in the longer term.

Acknowledgments: The lead author is grateful for the support they received from the China National Science Foundation for the project: A study of the impact of rural forestry reforms on the allocative efficiency of land-based production factors (71273211). All the authors appreciate the comments and suggestions made by the reviewers and Dr. Sun Joseph Chang, an Editor of this journal. 


\section{References}

Bennett, M.T., 2008. China's sloping land conversion program: institutional innovation or business as usual? Ecological Economics 65(4): 699-711.

Finkelstein, A., 2007. The aggregate effects of health insurance: Evidence from the introduction of medicare. The Quarterly Journal of Economics 122(1): 1-37.

Furno, M., 2013. Quantile regression and structural change in the Italian wage equation. Economic Modelling 30: 420-434.

Groom, B., Palmer, C., 2012. REDD+ and rural livelihoods. Biological Conservation 154: 4252.

Koenker, R., Bassett, G., 1978. Regression quantiles. Econometrica 46(1): 33-50.

Li, J., Feldman, M.W., Li, S.Z., Daily, G.C., 2011. Rural household income and inequality under the Sloping Land Conversion Program in western China. Proceedings of the National Academy of Sciences of the USA 108(19): 7721-7726.

Lin, Y., Yao, S.B., 2014. Impact of the Sloping Land Conversion Program on rural household income: an integrated estimation. Land Use Policy 40: 56-63.

Liu, C., Lu, J.Z., Yin, R.S., 2010. An estimation of the effects of China's forestry programs on farmers' income. Environmental Management 45: 526-540.

Liu, C., Wang, S., Liu, H., Zhu, W.Q., 2013.The impact of China's Priority Forest Programs on rural households' income mobility. Land Use Policy 31: 237-248.

Liu, C., Zhang, W., 2006. Impacts of Conversion of Farmland to Forestland Program on household income: evidence from a Sand Control Program in the vicinity of Beijing and Tianjin. China Economic Quarterly 6(1): 273-290 (in Chinese).

Liu, J.G., Li, S.X., Ouyang, Z.Y., Tam, C., Chen, X.D., 2008. Ecological and socioeconomic effects of China's policies for ecosystem services. Proceedings of the National Academy of Sciences of the USA 105: 9477-9482.

Meyer, B.D., Sullivan, J.X., 2013. Consumption and income inequality and the Great Recession. American Economic Review 103(3): 178-183.

State Forestry Administration (SFA), 2003. China Forestry Development Report 2002. Forestry Press, Beijing, China.

State Forestry Administration (SFA), 2013. China Forestry Development Report 2012.Forestry Press, Beijing, China. 
Uchida, E., Xu, J.T., Xu, Z.G., Rozelle, S., 2007. Are the poor benefiting from China's land conservation program? Environment and Development Economics 12: 593-620.

Uchida, E., Xu, J.T., Rozelle, S., 2005. Grain for green: cost-effectiveness and sustainability of China's conservation set-aside program. Land Economics 81(2): 247-264.

Wang, C.M., Maclaren, V., 2012. Evaluation of economic and social impacts of the sloping land conversion program: a case study in Dunhua County, China. Forest Policy and Economics $14: 50-57$.

Wooldridge, J.M., 2002. Econometric Analysis of Cross Section and Panel Data. Cambridge, MA: MIT Press.

Wuqi SLCP Office, 2012. A summary report of Wuqi's implementation of the Sloping Land Conversion Program.

Wuqi Statistics Bureau (1999-2012),1998-2011. Wuqi statistical yearbook

Xu, Z.J., Bennett, M., Tao, R., Xu, J.T., 2004. China's Sloping Land Conversion Program four years on: current situation, pending issues. International Forestry Review 6(4): 317-326.

Xu, J.T., Tao, R., Xu, Z.G., 2004. Sloping Land Conversion Program: cost-effectiveness, structural effect and economic sustainability. China Economic Quarterly 4(1): 139-162 (in Chinese).

Xu, J.T., Yin, R.S., Liu, C., Li, Z., 2006. China's ecological rehabilitation: Unprecedented efforts in uncharted territory. Ecological Economics 57: 595-607.

Yao, S.B., Guo, Y.J., Huo, X.X., 2010. An empirical analysis of effects of China's land conversion program on farmers' income growth and labor transfer. Environmental Management 45: 502-512.

Yi, F.J., Xu, J.T., Xu, Z.G., 2006. Reanalysis of the economic impact of the sloping land conversion program. China Rural Economy 10: 28-36 (in Chinese).

Yin, R.S., 2009. An Integrated Assessment of China's Ecological Restoration Programs. Springer, Dordrecht, The Netherlands.

Yin, R.S., Liu, T.J., Yao, S.B., Zhao, M.J., 2013. Designing and implementing payments for ecosystem services programs: lessons learned from China's cropland restoration experience. Forest Policy and Economics 35: 66-72.

Yin, R.S., Liu, C., Zhao, M.J., Yao, S.B., Liu, H., 2014. The implementation and impacts of China's largest payment for ecosystem services program as revealed by longitudinal household data. Land Use Policy 40: 45-55. 
Yin, R.S., Yin, G.P., 2010. China's ecological restoration: Initiation, implementation, and challenges. Environmental Management 45: 429-441.

Yin, R.S., Yin, G.P., Li, L.Y., 2010. Assessing China's ecological restoration programs: What's been done and what remains to be done? Environmental Management 45: 442-453.

Yin, R.S., Zhao, M.J., 2012. Ecological restoration programs and payments for ecosystem services as integrated social-ecological processes. Ecological Economics 73: 56-65.

Zhang, S.Q., Swanson, T., Kontoleon, A., 2005. Impacts of compensation policies in reforestation programs. Report of the environment and poverty programme to China council for international cooperation on environment and development.

Zhao, M.J., Yin, R.S., Yao, L.Y., Xu, T., 2015. Assessing the impact of China's Sloping Land Conversion Program on household production efficiency under spatial heterogeneity and output diversification. China Agricultural Economic Review 7(2): 221-239. 


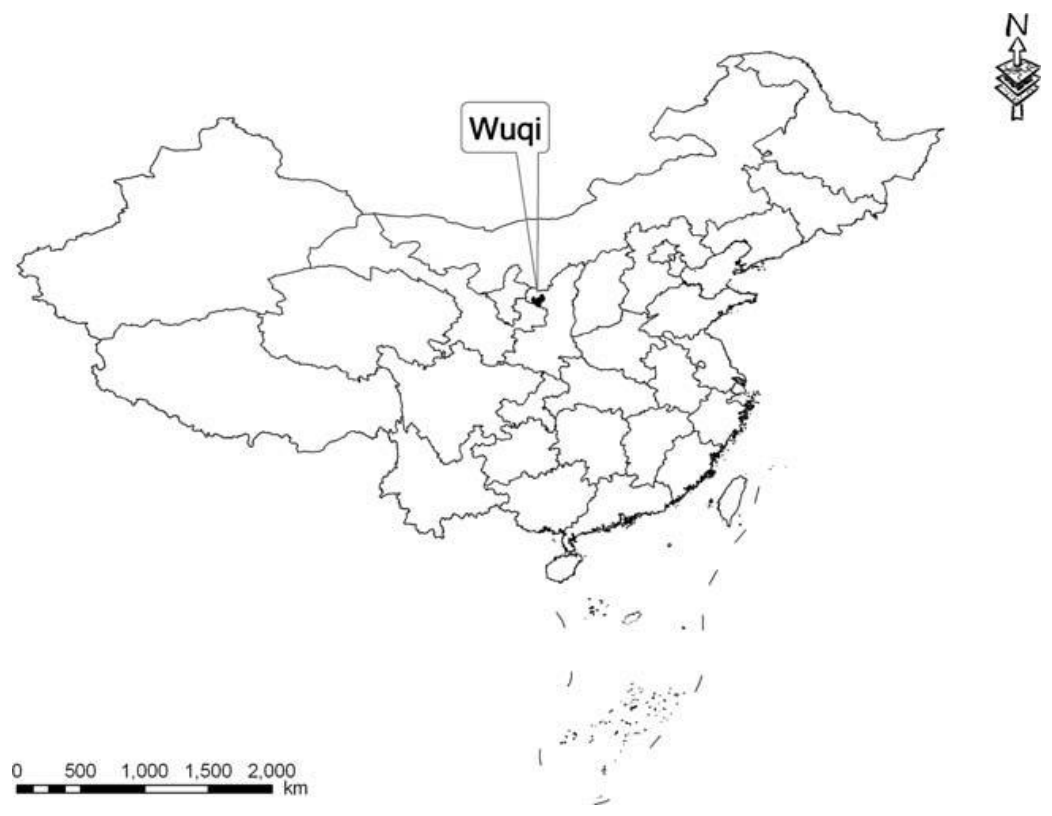

Figure 1. Location of the study site

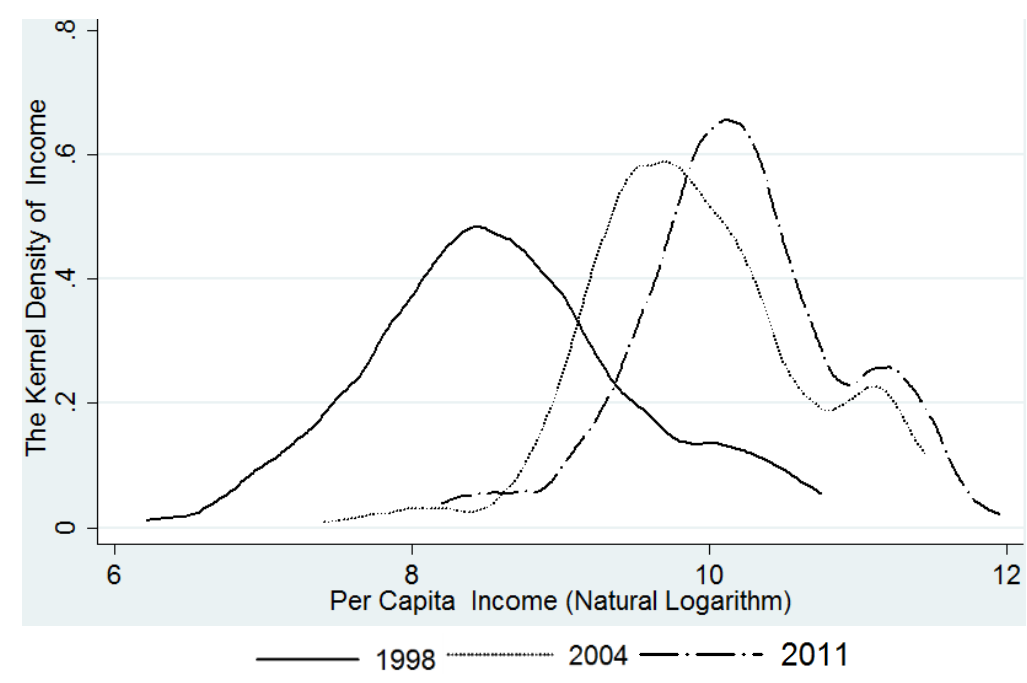

Figure 2. Distribution of farmers' per capita income and its shift over time 
Table 1. Farmers' per capita income from different sources in Wuqi (1998-2011) (unit: yuan)

\begin{tabular}{|c|c|c|c|c|c|c|}
\hline & Farming & $\begin{array}{c}\text { Farming } \\
\text { subsidy }\end{array}$ & $\begin{array}{c}\text { Animal } \\
\text { husbandry }\end{array}$ & $\begin{array}{c}\text { SLCP } \\
\text { subsidy }\end{array}$ & Off-farm & Total \\
\hline 1998 & 947 & 0 & 396 & 0 & 89 & 1432 \\
\hline 1999 & 603 & 0 & 116 & 481 & 114 & 1314 \\
\hline 2000 & 595 & 0 & 98 & 541 & 162 & 1396 \\
\hline 2001 & 572 & 0 & 87 & 567 & 203 & 1429 \\
\hline 2002 & 560 & 0 & 86 & 635 & 273 & 1554 \\
\hline 2003 & 525 & 0 & 96 & 734 & 333 & 1688 \\
\hline 2004 & 531 & 16 & 110 & 883 & 428 & 1968 \\
\hline 2005 & 520 & 16 & 104 & 941 & 876 & 2457 \\
\hline 2006 & 482 & 72 & 198 & 1031 & 858 & 2641 \\
\hline 2007 & 696 & 105 & 114 & 707 & 936 & 2658 \\
\hline 2008 & 652 & 174 & 141 & 769 & 1703 & 3619 \\
\hline 2009 & 676 & 184 & 189 & 644 & 1736 & 3729 \\
\hline 2010 & 717 & 182 & 186 & 645 & 1764 & 3894 \\
\hline 2011 & 695 & 213 & 180 & 643 & 1763 & 3794 \\
\hline
\end{tabular}

Notes:

1. The income figures, coming from the Wuqi Statistics Bureau (1998-2011), were deflated using the county's consumer price index based on 1990; using per-capita statistics is intended to avoid the confounding effect of variation of family size over time.

2. Farming income is income from producing corn, potatoes, and other minor crops; animal husbandry income is income from raising livestock; off-farm income is income from off-farm employment, mainly construction and services in local towns as well as large cities. Total income is the gross income from all sources. As a result of the existence of another minor category of income from other sources, these items do not add up to the total.

Table 2. Basic features of the surveyed households in Wuqi 


\begin{tabular}{lrrrr}
\hline & 1998 & 2004 & 2006 & 2011 \\
\hline Area enrolled in the SLCP & 0.00 & 2.57 & 2.74 & 2.74 \\
(ha) & $(0.00)$ & $(1.56)$ & $(1.87)$ & $(1.30)$ \\
Age of household head (year) & 44.48 & 47.84 & 49.57 & 55.89 \\
& $(10.42)$ & $(10.42)$ & $(10.85)$ & $(11.53)$ \\
Household head education & 4.51 & 5.51 & 5.57 & 5.92 \\
(year) & $(2.32)$ & $(3.87)$ & $(3.95)$ & $(3.57)$ \\
Family size (person) & 5.12 & 4.79 & 4.59 & 3.96 \\
& $(1.56)$ & $(1.56)$ & $(1.99)$ & $(1.28)$ \\
Number of laborers & 4.32 & 3.4 & 2.87 & 2.45 \\
& $(1.34)$ & $(1.35)$ & $(1.37)$ & $(1.06)$ \\
Cultivated land (ha) & 3.39 & 0.81 & 0.72 & 0.76 \\
& $(1.70)$ & $(0.35)$ & $(0.43)$ & $(0.49)$ \\
Farming expenditure (yuan) & 1900.3 & 1156.8 & 1144.69 & 1023.73 \\
& $(1078)$ & $(1271)$ & $(3979)$ & $(2232)$ \\
Farming time (day) & 486.26 & 191.36 & 123.97 & 118.56 \\
& $(2116.1)$ & $(159.77)$ & $(59.31)$ & $(47.67)$ \\
Off-farm work time (day) & 10.46 & 182.43 & 222.7 & 231.8 \\
& $(41.21)$ & $(123.24)$ & $(144.16)$ & $(173.48)$ \\
Destinations of off-farm work & 0.86 & 1.43 & 1.36 & 1.09 \\
& $(0.57)$ & $(1.05)$ & $(1.40)$ & $(1.47)$ \\
\hline
\end{tabular}

Notes:

1. 1998 is the last year before the Sloping Land Conversion Program (SLCP) was initiated, 2004 is the year when the SLCP enrollment was virtually completed, 2006 is the year when the original eight-year duration of the subsidy expired, and 2011 is the year of our last survey.

2. Figures in parentheses are standard deviations.

3. Working ages range from 18 to 65 .

4. Destinations for off-farm employment are defined as follows: 1 if inside the county, 2 if outside of the county but inside the province, and 3 if outside of the province.

5. All the values are in real terms, deflated by the county's Consumer Price Index (with 1998 as the base year). 
Table 3. Income composition and changes over time for groups with different levels of cropland retirement (unit: yuan/per capita)

\begin{tabular}{rrrrrrr}
\hline Year & $\begin{array}{c}\text { Enrolled } \\
\text { land(ha) }\end{array}$ & $\begin{array}{c}\text { SLCP } \\
\text { subsidy }\end{array}$ & Farming & $\begin{array}{c}\text { Animal } \\
\text { husbandry }\end{array}$ & $\begin{array}{c}\text { Off-farm } \\
\text { work }\end{array}$ & Total \\
\hline 1998 & $<1.3$ & 0 & 781.5 & 388.9 & 82.0 & 1252.5 \\
& $1.3-2.0$ & 0 & 965.7 & 338.0 & 84.2 & 1388.0 \\
& $>2.0$ & 0 & 1232.2 & 403.3 & 94.0 & 1729.5 \\
2004 & $<1.3$ & 563.1 & 451.5 & 132.5 & 402.5 & 1549.7 \\
& $1.3-2.0$ & 831.3 & 389.9 & 106.4 & 440.2 & 1767.7 \\
& $>2.0$ & 1715.2 & 742.2 & 119.6 & 658.9 & 3235.9 \\
2006 & $<1.3$ & 567.3 & 898.0 & 181.1 & 675.4 & 2321.8 \\
& $1.3-2.0$ & 835.0 & 672.5 & 159.9 & 794.6 & 2461.9 \\
& $>2.0$ & 1707.8 & 392.7 & 256.4 & 1125.5 & 3482.4 \\
& & & & & & \\
2011 & $1.3-2.0$ & 503.5 & 932.9 & 129.2 & 1663.5 & 3229.2 \\
& $>2.0$ & 1157.7 & 536.1 & 343.0 & 2676.1 & 4712.8 \\
\hline
\end{tabular}

Notes:

1. Dividing retired cropland into the three different levels is based on its distribution in the sample, the purpose of which is to show the different economic dynamics associated with the different levels.

2. Farming income is income from producing corn, potatoes, and other minor crops; animal husbandry income is income from raising livestock; off-farm income is income from off-farm employment, mainly construction and services in local towns as well as large cities. For convenience, farming subsidies are included in farming income here. Total income is the gross income from all sources.

3. The income figures were deflated using the county's producer price index based on 1998. 
Table 4. Regression results for the period of 1998-2011

\begin{tabular}{|c|c|c|c|c|c|}
\hline \multirow{2}{*}{$\begin{array}{l}\text { Independent } \\
\text { variables }\end{array}$} & \multirow[t]{2}{*}{ Lumped data } & \multicolumn{4}{|c|}{ Quantiles } \\
\hline & & 0.25 & 0.50 & 0.75 & 0.90 \\
\hline$X_{1}$ & $0.14(1.89)^{*}$ & $0.25(3.15)^{* * *}$ & $0.20(2.02)^{* *}$ & $0.13(1.71)$ & $0.09(1.32)$ \\
\hline$X_{2}$ & $0.01(1.32)$ & $0.03(1.93)^{* *}$ & $0.01(1.23)$ & $0.00(0.57)$ & $-0.03(1.12)$ \\
\hline$X_{3}$ & $0.31(4.21)^{* * *}$ & $0.52(5.48)^{* * *}$ & $0.27(4.32)^{* * *}$ & $0.10(7.87)^{* * *}$ & $0.07(2.14)^{* *}$ \\
\hline$X_{4}$ & $0.03(1.52)$ & $0.07(2.53)^{* *}$ & $0.05(1.76)^{*}$ & $0.02(1.58)$ & $-0.07(1.28)$ \\
\hline$X_{5}$ & $0.54(2.45)^{* * *}$ & $0.39(2.12)^{* *}$ & $0.45(3.34)^{* * *}$ & $0.65(3.15)^{* * *}$ & $0.94(6.12)^{* * *}$ \\
\hline$X_{6}$ & $0.18(3.16)^{* * *}$ & $0.10(1.82)^{*}$ & $0.11(2.01)^{* *}$ & $0.21(3.54)^{* * *}$ & $0.28(2.43)^{* * *}$ \\
\hline$X_{7}$ & $0.12(3.11)^{* * *}$ & $0.07(1.67)^{*}$ & $0.11(2.18)^{* *}$ & $0.15(2.45)^{* *}$ & $0.19(4.44)^{* * *}$ \\
\hline$X_{8}$ & $0.13(2.53)^{* *}$ & $0.11(1.11)$ & $0.11(1.69)^{*}$ & $0.10(2.34)^{* *}$ & $0.14(4.24)^{* * *}$ \\
\hline$X_{9}$ & $0.23(2.33)^{* *}$ & $0.44(3.65)^{* * *}$ & $0.40(3.73)^{* * *}$ & $0.18(2.18)^{* *}$ & $0.11(1.83)^{*}$ \\
\hline$X_{10}$ & $0.78(5.31)^{* * *}$ & $0.44(1.85)^{*}$ & $0.57(2.43)^{* *}$ & $0.70(6.48)^{* * *}$ & $0.88(7.88)^{* * *}$ \\
\hline$X_{11}$ & $0.03(1.31)$ & $0.05(2.05)^{* *}$ & $0.03(1.81) *$ & $0.01(1.51)$ & $0.00(1.23)$ \\
\hline$X_{12}\left(X_{6} \times X_{10}\right)$ & $0.53(2.41)^{* *}$ & $0.41(1.76)^{*}$ & $0.48(2.54)^{* *}$ & $0.57(7.81)^{* * *}$ & $0.69(5.31)^{* * *}$ \\
\hline$T_{1}$ & $0.28(2.24) * *$ & $0.18(1.73)^{*}$ & $0.26(2.14) * *$ & $0.31(3.61)^{* * *}$ & $0.43(2.87)^{* * *}$ \\
\hline$T_{2}$ & $0.39(5.51) * * *$ & $0.23(3.11)^{* * *}$ & $0.32(3.94)^{* * *}$ & $0.41(5.98)^{* * *}$ & $0.51(6.28)^{* * *}$ \\
\hline$T_{3}$ & $0.22(2.08) * *$ & $0.15(2.11)^{* *}$ & $0.26(2.15)^{* *}$ & $0.41(3.09)^{* * *}$ & $0.32(1.81)^{*}$ \\
\hline$T_{1} \times X_{1}$ & $0.13(2.32)^{* *}$ & $0.10(1.78)^{*}$ & $0.12(2.05)^{* *}$ & $0.16(3.19)^{* * *}$ & $0.18(6.23)^{* * *}$ \\
\hline$T_{2} \times X_{1}$ & $0.17(3.15)^{* * *}$ & $0.13(2.23)^{* *}$ & $0.15(2.87)^{* * *}$ & $0.21(4.84)^{* * *}$ & $0.24(3.43)^{* * *}$ \\
\hline$T_{3} \times X_{1}$ & $0.08(2.02)^{* *}$ & $0.11(3.39)^{* * *}$ & $0.10(2.18)^{* *}$ & $0.07(1.75)^{*}$ & $0.05(1.81)^{*}$ \\
\hline Adjusted $R^{2}$ & 0.62 & 0.59 & 0.61 & 0.63 & 0.60 \\
\hline
\end{tabular}

Notes:

1. $Y$ is household income (in natural logarithm); $X_{1}, X_{2}, X_{3}, X_{4}$ and $X_{5}$ (all in natural logarithm) are household's subsidy of the SLCP, area of cultivated land, farming expenditure, farming time, and off-farm work time; $X_{6}$ is the ratio of off-farm labor to total labor, $X_{7}$ the destination of off-farm work ( 1 if it is inside the county, 2 outside of the county but inside the province, and 3 outside of the province), $X_{8}$ the number of family laborers, $X_{9}$ township's per capita GDP (in natural logarithm), $X_{10}$ the ratio of retired cropland to total cropland area in 1998 for each township, $X_{11}$ the ratio of farming subsidy to total income, and $X_{12}$ the product of $X_{6}$ and $X_{10} ; T$ is a set of time dummy variables $\left(T_{1}=1\right.$ for 2004, 0 otherwise; $T_{2}=1$ for 2006, 0 otherwise; $T_{3}=1$ for 2011, 0 otherwise).

2. The total observations used were 728 .

3. Figures in parentheses are $t$ statistics; $*, * *$, and $* * *$ denote significance at $10 \%, 5 \%$, and 
$1 \%$ levels, respectively.

Table 5. Regression results for the period of 1998-2004

\begin{tabular}{|l|l|l|l|l|l|}
\hline \multirow{2}{*}{$\begin{array}{l}\text { Independent } \\
\text { variables }\end{array}$} & \multirow{2}{*}{ Lumped data } & \multicolumn{4}{|c|}{ Quantiles } \\
\cline { 3 - 6 } & & \multicolumn{1}{|c|}{$\mathbf{0 . 2 5}$} & $\mathbf{0 . 5 0}$ & \multicolumn{1}{|c|}{$\mathbf{0 . 7 5}$} & \multicolumn{1}{c|}{$\mathbf{0 . 9 0}$} \\
\hline$X_{1}$ & $0.25(4.28)^{* * *}$ & $0.33(3.64)^{* * *}$ & $0.18(3.32)^{* * *}$ & $0.20(4.33)^{* * *}$ & $0.40(9.23)^{* * *}$ \\
\hline$X_{2}$ & $0.01(2.01)^{*}$ & $0.02(2.12)^{* *}$ & $0.03(2.43)^{* *}$ & $0.02(1.31)$ & $0.00(1.29)$ \\
\hline$X_{3}$ & $0.38(7.92)^{* * *}$ & $0.63(5.52)^{* * *}$ & $0.32(5.31)^{* * *}$ & $0.23(6.15)^{* * *}$ & $0.11(4.18)^{* * *}$ \\
\hline$X_{4}$ & $0.09(1.81)^{*}$ & $0.16(2.21)^{* *}$ & $0.11(2.09)^{* *}$ & $0.07(1.43)$ & $0.03(1.37)$ \\
\hline$X_{5}$ & $0.54(2.12)^{* *}$ & $0.34(1.75)^{*}$ & $0.38(2.26)^{* *}$ & $0.62(3.32)^{* * *}$ & $1.03(4.62)^{* * *}$ \\
\hline$X_{6}$ & $0.95(2.18)^{* *}$ & $0.61(1.98)^{*}$ & $0.77(2.31)^{* *}$ & $1.03(7.72)^{* * *}$ & $1.27(5.61)^{* * *}$ \\
\hline$X_{7}$ & $0.19(1.82)^{*}$ & $0.14(1.35)$ & $0.17(1.78)^{*}$ & $0.20(2.37)^{* *}$ & $0.32(2.36)^{* *}$ \\
\hline$X_{8}$ & $0.04(9.21)^{* * *}$ & $0.08(5.43)^{* * *}$ & $0.05(3.40)^{* * *}$ & $0.03(4.22)^{* * *}$ & $0.01(4.73)^{* * *}$ \\
\hline$X_{9}$ & $1.74(6.87)^{* * *}$ & $0.95(6.23)^{* * *}$ & $1.00(4.44)^{* * *}$ & $2.04(5.76)^{* * *}$ & $2.65(3.69)^{* * *}$ \\
\hline$X_{10}$ & $0.78(6.66)^{* * *}$ & $0.65(3.43)^{* *}$ & $0.74(7.76)^{* * *}$ & $0.83(4.13)^{* * *}$ & $1.74(6.08)^{* * *}$ \\
\hline$X_{11}$ & $0.01(1.53)$ & $0.03(1.95)^{*}$ & $0.02(1.57)$ & $0.00(1.52)$ & $0.00(1.39)$ \\
\hline$X_{12}\left(X_{6} \times X_{10}\right)$ & $0.77(6.23)^{* * *}$ & $0.28(1.69)^{*}$ & $0.41(2.22)^{* *}$ & $0.82(7.32)^{* * *}$ & $1.12(4.65)^{* * *}$ \\
\hline$T$ & $0.35(2.41) * *$ & $0.33(1.82)^{*}$ & $0.28(2.43)^{* *}$ & $0.39(3.57) * * *$ & $0.48(2.72)^{* * *}$ \\
\hline$T \times X_{1}$ & $0.22(2.41)^{* *}$ & $0.12(1.93)^{*}$ & $0.18(2.39)^{* *}$ & $0.37(4.72)^{* * *}$ & $0.47(6.77)^{* * *}$ \\
\hline Adjusted $R^{2}$ & 0.56 & 0.54 & 0.59 & 0.53 & 0.55 \\
\hline & & & & & \\
\hline
\end{tabular}

Notes:

1. $Y$ is household income (in natural logarithm); $X_{1}, X_{2}, X_{3}, X_{4}$ and $X_{5}$ (all in natural logarithm) are household's subsidy of the SLCP, area of cultivated land, farming expenditure, farming time, and off-farm work time; $X_{6}$ is the ratio of off-farm labor to total labor, $X_{7}$ the destination of off-farm work ( 1 if it is inside the county, 2 outside of the county but inside the province, and 3 outside of the province), $X_{8}$ the number of family laborers, $X_{9}$ township's per capita GDP (in natural logarithm), $X_{10}$ the ratio of retired cropland to total cropland area in 1998 for each township, $X_{11}$ the ratio of farming subsidy to total income, and $X_{12}$ the product of $X_{6}$ and $X_{10} ; T$ is a time dummy (1 for 2004, 0 otherwise).

2. The total observations used in the regressions were 364 .

3. Figures in parentheses are $t$ statistics; *, **, and $* * *$ denote significance at $10 \%, 5 \%$, and $1 \%$ levels, respectively. 
Table 6. Regression results for the period of 2006-2011

\begin{tabular}{|l|l|l|l|l|l|}
\hline \multirow{2}{*}{$\begin{array}{l}\text { Independent } \\
\text { variables }\end{array}$} & \multirow{2}{*}{ Lumped data } & \multicolumn{4}{|c|}{ Quantiles } \\
\cline { 3 - 6 } & & \multicolumn{1}{|c|}{$\mathbf{0 . 2 5}$} & $\mathbf{0 . 5 0}$ & \multicolumn{1}{|c|}{$\mathbf{0 . 7 5}$} & \multicolumn{1}{|c|}{$\mathbf{0 . 9 0}$} \\
\hline$X_{1}$ & $0.14(2.07)^{* *}$ & $0.19(4.28)^{* * *}$ & $0.15(8.24)^{* * *}$ & $0.12(1.39)$ & $0.09(1.54)$ \\
\hline$X_{2}$ & $0.00(0.99)$ & $0.01(0.76)$ & $0.00(0.63)$ & $-0.01(0.79)$ & $-0.03(0.96)$ \\
\hline$X_{3}$ & $0.27(4.78)^{* * *}$ & $0.52(6.43)^{* * *}$ & $0.37(6.32)^{* * *}$ & $0.07(4.76)^{* * *}$ & $0.03(3.76)^{* * *}$ \\
\hline$X_{4}$ & $0.03(1.34)$ & $0.08(1.72)^{*}$ & $0.04(0.46)$ & $0.00(0.94)$ & $-0.01(0.83)$ \\
\hline$X_{5}$ & $0.67(2.21)^{* *}$ & $0.48(1.83)^{*}$ & $0.59(2.37)^{* *}$ & $0.99(6.11)^{* * *}$ & $1.27(6.82)^{* * *}$ \\
\hline$X_{6}$ & $1.42(2.27)^{* *}$ & $1.21(1.75)^{*}$ & $1.33(2.18)^{* *}$ & $1.38(8.42)^{* * *}$ & $1.67(8.85)^{* * *}$ \\
\hline$X_{7}$ & $0.12(1.78)^{*}$ & $0.13(0.20)$ & $0.11(1.81)^{*}$ & $0.13(1.89)^{*}$ & $0.20(2.14)^{* *}$ \\
\hline$X_{8}$ & $0.13(1.66)$ & $0.18(1.59)$ & $0.10(1.36)$ & $0.11(1.87)^{*}$ & $0.21(2.41)^{* *}$ \\
\hline$X_{9}$ & $1.90(7.43)^{* * *}$ & $1.01(6.02)^{* * *}$ & $1.50(3.23)^{* * *}$ & $2.61(5.45)^{* * *}$ & $3.48(6.85)^{* * *}$ \\
\hline$X_{10}$ & $1.17(5.76)^{* * *}$ & $0.78(2.20)^{* *}$ & $1.05(7.51)^{* * *}$ & $1.29(7.86)^{* * *}$ & $1.54(8.31)^{* * *}$ \\
\hline$X_{11}$ & $0.05(1.76)^{*}$ & $0.07(3.17)^{* * *}$ & $0.06(1.92)^{*}$ & $0.03(1.63)$ & $0.01(1.54)$ \\
\hline$X_{12}\left(X_{6} \times X_{10}\right)$ & $0.93(2.18)^{* *}$ & $0.78(1.73)^{*}$ & $0.87(2.27)^{* *}$ & $1.02(5.28)^{* * *}$ & $1.17(8.75)^{* * *}$ \\
\hline$T$ & $0.24(2.32)^{* *}$ & $0.10(1.89)^{*}$ & $0.22(2.27)^{* *}$ & $0.28(4.16)^{* * *}$ & $0.39(4.23)^{* * *}$ \\
\hline$T \times X_{1}$ & $0.04(2.31)^{* *}$ & $0.06(3.14)^{* * *}$ & $0.04(2.28)^{* *}$ & $0.03(1.84)^{*}$ & $0.04(1.67)^{*}$ \\
\hline Adjusted $R^{2}$ & 0.51 & 0.55 & 0.50 & 0.57 & 0.55 \\
\hline
\end{tabular}

Notes:

1. $Y$ is household income (in natural logarithm); $X_{1}, X_{2}, X_{3}, X_{4}$ and $X_{5}$ (all in natural logarithm) are household's subsidy of the SLCP, area of cultivated land, farming expenditure, farming time, and off-farm work time; $X_{6}$ is the ratio of off-farm labor to total labor, $X_{7}$ the destination of off-farm work ( 1 if it is inside the county, 2 outside of the county but inside the province, and 3 outside of the province), $X_{8}$ the number of family laborers, $X_{9}$ township's per capita GDP (in natural logarithm), $X_{10}$ the ratio of retired cropland to total cropland area in 1998 for each township, $X_{11}$ the ratio of farming subsidy to total income, and $X_{12}$ the product of $X_{6}$ and $X_{10}$; $T$ is a time dummy (1 for 2011, 0 otherwise).

2. The total observations used in the regressions were 364 .

3. Figures in parentheses are $t$ statistics; $*$, **, and $* * *$ denote significance at $10 \%, 5 \%$, and $1 \%$ levels, respectively. 